\title{
Therapeutic approach targeting apolipoprotein E binding region and low-density lipoprotein receptor for Alzheimer's disease
}

\author{
Michael Leon ${ }^{1}$, Darrell Sawmiller ${ }^{1}$, Brian Giunta ${ }^{2}$, Jun Tan ${ }^{1}$ \\ 'Rashid Laboratory for Developmental Neurobiology, Silver Child Development Center, Department of Psychiatry and Behavioral \\ Neurosciences, Morsani College of Medicine, University of South Florida, Tampa, FL 33613, USA. \\ ${ }^{2}$ Neuroimmunology Laboratory, Department of Psychiatry and Behavioral Neurosciences, Morsani College of Medicine, University of \\ South Florida, Tampa, FL 33613, USA.
}

Correspondence to: Dr. Michael Leon, Rashid Laboratory for Developmental Neurobiology, Silver Child Development Center, Department of Psychiatry and Behavioral Neurosciences, Morsani College of Medicine, University of South Florida, 3515 E Fletcher Ave, Tampa, FL 33613, USA. E-mail: mleon@health.usf.edu

How to cite this article: Leon M, Sawmiller D, Giunta B, Tan J. Therapeutic approach targeting apolipoprotein E binding region and low-density lipoprotein receptor for Alzheimer's disease. Neuroimmuno/ Neuroinflammation 2018;5:30.

http://dx.doi.org/10.20517/2347-8659.2018.26

Received: 8 May 2018 First Decision: 11 Jun 2018 Revised: 19 Jul 2018 Accepted: 20 Jul 2018 Published: 31 Jul 2018

Science Editor: Athanassios P. Kyritsis Copy Editor: Jun-Yao Li Production Editor: Huan-Liang Wu

\begin{abstract}
Approximately $13 \%$ of the population over the age of 65 years is estimated to have AD. The total number of cases is expected to increase over the coming decades. The apolipoprotein $E$ (ApoE) genotype is the greatest genetic determinant for Alzheimer's disease (AD) development. The ApoE4 allele increases the risk of AD by 4 to 14 fold while the ApoE2 allele has an opposing effect; decreasing risk. Indeed many studies have demonstrated that carriers of the ApoE2 allele are associated with greater likelihood of survival to advanced age, superior verbal learning ability in advanced age, and reduced accumulation of amyloid pathology in the aged brain. In addition, it is known that ApoE proteins have different affinities for the low-density lipoprotein receptor (LDLR), with ApoE2 having the weakest binding to the LDL receptor at $<2 \%$ relative to ApoE3 and E4. Because ApoE2 has shown protective effects in regard to $A D$, a novel approach for ApoE4 carriers may be to create a peptide antagonist that blocks the ApoE interactions with LDLR at its 135-150 N-terminal binding domain. This peptide may create a more ApoE2-like structure by decreasing the affinity of ApoE4 for LDLR thereby reducing AD onset, memory impairment, and amyloid plaque formation. In this review, we will discuss the different detrimental effects that ApoE4 can cause. Most importantly, we will review how ApoE4 binding to LDLR promotes AD pathogenesis and how blocking ApoE4 binding may be a promising novel therapeutic approach for AD.
\end{abstract}

Keywords: Alzheimer's disease, low-density lipoprotein receptor, apolipoprotein E, amyloid precursor protein, late onset Alzheimer's disease

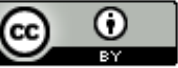

(C) The Author(s) 2018. Open Access This article is licensed under a Creative Commons Attribution 4.0 International License (https://creativecommons.org/licenses/by/4.0/), which permits unrestricted use, sharing, adaptation, distribution and reproduction in any medium or format, for any purpose, even commercially, as long as you give appropriate credit to the original author(s) and the source, provide a link to the Creative Commons license, and indicate if changes were made.

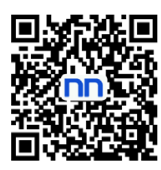




\section{INTRODUCTION TO APOE}

As life expectancies increase, more elderly patients are diagnosed with Alzheimer's disease (AD). AD brain exhibits close to 50\% neuron loss in the cortex. Genome-wide association studies (GWAS) have identified the apolipoprotein $\mathrm{E}$ (ApoE) gene as a risk factor for $\mathrm{AD}^{[1,2]}$. It has been found that there is a strong correlation between ApoE4 carriers and higher levels of amyloid pathology. However, individuals who do not carry the ApoE4 allele seem to demonstrate fewer AD disease processes or other neurodegenerative disorders ${ }^{[3-6]}$.

The human ApoE gene is encoded on chromosome 19. ApoE is a 34-kDa protein consisting of 299 amino acids and is constitutively expressed in astrocytes, microglia, vascular smooth muscle cells, and choroid plexus while neurons typically generate ApoE under stress conditions. Through mRNA studies it has been demonstrated that the liver is the major producer of ApoE, followed next by the brain. The receptor-binding domain of ApoE is located within amino acids 136-150 of the N-terminal region. There are three different human isoforms of ApoE (ApoE2, ApoE3, and ApoE4) which differ by only 2 amino acids at sites 112 and 158. ApoE2 has cysteines located at both sites, ApoE3 has a cysteine at site 112 and arginine at site 158 while ApoE4 has arginines at both sites ${ }^{[7,8]}$. The heterogeneous nature of the three isoforms is secondary to genetic polymorphisms ${ }^{[9]}$. It has been shown that there is a linear reduction in brain hippocampal volumes by magnetic resonance imaging (MRI) scans according to ApoE genotype in the following hierarchy: ApoE4 < ApoE3 < ApoE2. In AD patients, ApoE4 carriers had significantly smaller hippocampal volume compared to ApoE2 carriers. This study used several well-characterized cohorts to analyze the neuroanatomic effect of ApoE on the left and right hippocampal volumes ${ }^{[10]}$. In addition, research has shown that the E4 allele is also a risk factor for atherosclerosis, human immunodeficiency virus (HIV) disease progression, cerebral amyloid angiography (CAA), tauopathies, dementia with Lewy bodies, and Parkinson's disease ${ }^{[1]]}$.

\section{APOE4 MECHANISM}

ApoE4 increases the risk of developing AD by 4 -fold with one allele and 14-fold with two alleles ${ }^{[12]}$. The approximate allele frequencies of $\mathrm{E} 2, \mathrm{E} 3$, and $\mathrm{E} 4$ in the human population are $7 \%, 78 \%$, and $14 \%$, respectively ${ }^{[6,13]}$. Moreover, it has been shown through histological analyses of AD brains that ApoE is co-deposited with amyloid-beta $(\mathrm{A} \beta)$ in amyloid plaques ${ }^{[14]}$. It has also been revealed that $\mathrm{A} \beta$ clearance is faster in ApoE3 transgenic mice versus ApoE4 transgenic mice ${ }^{[15]}$. This is likely because ApoE4 has an altered structure compared with ApoE2 or ApoE3, which alters its function. Therefore, understanding the structural properties of ApoE and its isoforms is vital to creating a prophylactic or therapeutic treatment. Research has shown that competition assays with ApoE4, ApoE3, and Tau revealed that ApoE4 inhibits Tau degradation. In addition, a single nucleotide polymorphism rs429358 defines ApoE4 and is located within exon 4 of apolipoprotein E. In regard to ApoE4, the arginine at position 112 directly influences arginine-61, which allows for domain interaction with glutamine-255. In addition, this bulky charged arginine residue destabilizes the N-terminal helix bundle domain, inducing helix shortening between amino acids 12 and 20 of the N-terminal domain and residues 204 and 210 of the C-terminal domain which reduces ApoE4 ability to form tetramers. This results in ApoE4 binding preference for very low-density lipoprotein (VLDL) $)^{[16-20]}$.

\section{APOE AND THE LOW-DENSITY LIPOPROTEIN RECEPTOR INTERACTION}

LDLR is one member of a family of seven core LDL receptor-related proteins (LRPs), which also includes LDLR-related protein 1 (LRP1), the VLDL receptor (VLDLR), megalin (LRP2), apolipoprotein E receptor 2 (ApoER2), and LRP4. All LDL receptor family members share structural properties that allow interaction with $\mathrm{ApoE}^{[21]}$. In addition, LDL receptor family members contain a transmembrane domain which can be endocytosed, proteolytically processed, and interact with cell proteins, including direct interaction with (amyloid precursor protein) APP ${ }^{[22]}$. LDLR, VLDLR, LRP, and ApoER2 are present in a number of brain cells including astrocytes, microglia, neurons, and oligodendrocytes ${ }^{[23]}$. It has also been reported that overexpres- 
sion of LDLR decreases ApoE levels in the brain, while LDLR deficient mice have increased ApoE brain accumulation $^{[24,25]}$. Further, LDLR overexpression elevates uptake of $A \beta$ in astrocytes. Conversely, deletion of LDLR has an opposing effect ${ }^{[26]}$. Upon culturing brain sections with $A \beta$ plaques with murine astrocytes, $A \beta$ was taken up and degraded via LDL receptor or LDL receptor related protein ${ }^{[27]}$. ApoE contains 299 residues and was identified as a main component of lipoproteins in plasma. It has been established that lysine and arginine residues situated between ApoE residues 136 and 150 interact directly with acidic residues in the ligand binding domain of LDLR. In addition, full receptor binding activity requires arginine at position 172 located at the hinge region that connects the $\mathrm{N}$ - and C-terminal domains. ApoE3 and ApoE4 bind to LDL receptors with high affinity, but the binding of ApoE2 is 50- to 100-times weaker ${ }^{[28]}$. These data suggest that ApoE4 confers the highest risk for AD pathology due to its increased affinity for LDLR.

Recent research has shown that ApoE binding to ApoE receptors increases transcription of $A \beta$ through activation of the mitogen activated protein (MAP) kinase signaling pathway involving dual leucine-zipper kinase (DLK). In fact, ApoE binding to cell-surface ApoE receptors activates DLK. The levels of A $\beta$ potency production increase according to the different human ApoE isoforms (ApoE4 $>$ ApoE3 $>$ ApoE2). Specifically, when ApoE binds to ApoE receptor, DLK is activated. DLK will then activates dual specificity mitogenactivated protein kinase kinase 7 (MKK7) and extracellular signal-regulated protein kinase (ERK) 1/2 MAP kinases. Further more, activated ERK1/2 induces cFos phosphorylation, that will eventually stimulate the transcription factor activation protein (AP)-1. Transcription factor AP-1 will enhance transcription of APP and thereby increase $A \beta$ levels ${ }^{[29]}$. Therefore, a peptide or antibody blocking the interaction between LDLR and the ApoE binding site may potentially decrease the MAP kinase cascade and APP transcription, ultimately leading to a decrease in $A \beta$ production. Previous research demonstrated that the monoclonal antibody $1 \mathrm{D} 7$ is specific for human ApoE and blocks binding of lipid-associated ApoE to $\mathrm{LDLR}^{[30]}$. 2E8 monoclonal antibody also binds to ApoE and prevents ApoE-mediated binding of lipoproteins to the LDLR ${ }^{[31]}$.

\section{APOE2-LIKE PROPERTIES AND BENEFITS}

Although ApoE2 known to cause type III hyperlipoproteinemia, the E2 allele is known for being protective against the development of late onset Alzheimer's disease (LOAD) compared to the common E3 and E4 allele as exemplified by a delayed age of onset and a greater likelihood of survival to advanced age. A cross-sectional multimodal neuroimaging approach has shown ApoE2 to be protective in the aged brain. In addition, the ApoE2 allele appears to have a relatively selective effect on reduced accumulation of amyloid pathology in the aged brain ${ }^{[32-34]}$. It has been reported that ApoE2 can promote type III hypercholesterolemia, leading to increased cardiovascular disease. However, studies demonstrate that ApoE4 knock-in mice have lower than normal brain cholesterol concentrations even though peripheral cholesterol levels are increased. This finding suggests that brain ApoE metabolism is distinct from that in the plasma. Moreover, the blood-brain barrier (BBB) effectively prevents the exchange of brain tissue and plasma lipoproteins. Thus, peripheral cholesterol cannot cross the BBB and enter the brain. Brain cholesterol is mainly synthesized in situ and provided by de novo synthesis, primarily by astrocytes and oligodendrocytes ${ }^{[11,32-35]}$.

ApoE2 is associated with slower cognitive decline, milder A $\beta$ pathology, and less neurodegeneration compared to ApoE3 and ApoE4. Older individuals who are ApoE2 carriers display superior verbal learning abilities, and faster processing of information. Possession of at least one copy of the ApoE2 allele has demonstrated a slower decline in episodic memory ${ }^{[34,36]}$. All isoforms of ApoE can modulate A $\beta$ clearance. However, aging APP transgenic mice expressing human ApoE2 also have the slowest rate of production of A $\beta$ oligomers with neuritic plaque formation compared to ApoE3 and ApoE4 mice ${ }^{[37]}$.

Rats expressing human ApoE2 have been shown to be protected from apoptotic death of cortical neurons induced by $\mathrm{A} \beta$ peptides $^{[38]}$. ApoE2 mice are also more effective in clearing $\mathrm{A} \beta$ from the bloodstream and pro- 
A ApoE4 binding to LDL receptor with increased affinity causing $A D$ pathology

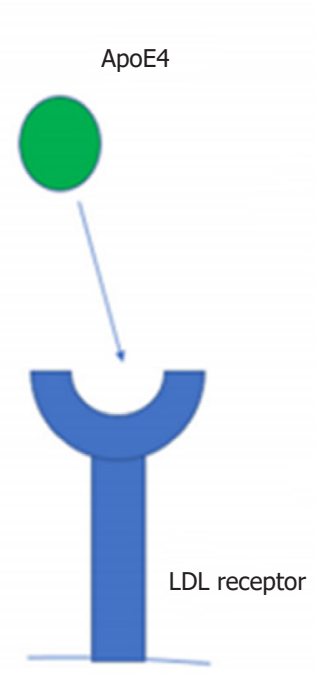

Cell membrane
B

ApoE4 binding affinity to LDL receptor decreases if a peptide is introduced acting as an competitive antagonist

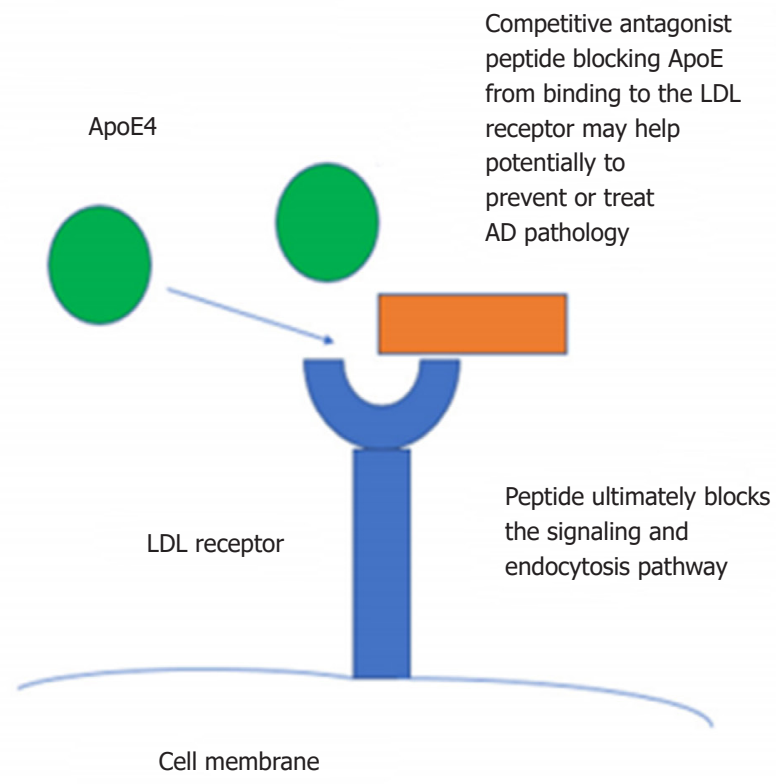

Figure 1. (A) ApoE4 has a 50 fold increased binding affinity to LDL receptor compared to ApoE2 (B). A novel approach is to create a peptide targeting the ApoE LDLR binding domain. This peptide can work as a competitive antagonist for patients who are ApoE4 carriers. Blocking the effect of ApoE4 binding affinity can help create a more ApoE2-like structure. ApoE2 is known to be protective in AD

moting degradation of $A \beta$. In addition, ApoE2 carriers have increased dendritic outgrowth, which enhances the formation of new synapses and can protect against AD synaptic deterioration ${ }^{[34,39]}$. Further, ApoE2 protected cultured cells most effectively, compared to the other ApoE isoforms, from oxidative stress-induced death in vitro ${ }^{[40]}$. The cysteine to arginine substitution at position 158 in ApoE2 makes ApoE2 more stable to thermal and chemical denaturation, compared to ApoE3 and ApoE4. Moreover, the cysteine residue at position 112 creates a lesser chance to exhibit domain interactions relative to $\mathrm{ApoE} 4^{[34,41,42]}$. It has been suggested that the development of drugs that can prevent the domain interaction of ApoE4 and convert ApoE4 to a more ApoE3/ApoE2-like structure may be beneficial for individuals with neurodegenerative disorders. In addition, a peptide blocking the 135-150 N-terminal region may create a more ApoE2-like structure, as ApoE2 has decreased affinity for the LDLR. Given that ApoE2 carriers have a lower risk and delayed age of onset of $\mathrm{AD}$ compared to $\mathrm{E} 3$ and $\mathrm{E} 4$ carriers $^{[11,34,43]}$, it would stand to reason that creating a more ApoE2 structure can be beneficial for treating AD rather than using ApoE E3 or ApoE4 structures.

\section{CONCLUSION}

Currently approximately 5.1 million Americans are affected with AD and the number is expected to triple by 2050. Further there are no truly effective disease-modifying therapies for AD. ApoE4 is known to play a major role not only in $\mathrm{AD}$, but also atherosclerosis, CAA, tauopathies, dementia with Lewy bodies, and stroke. Approximately the allele frequencies of E2, E3, and E4 in the human population are 7\%, 78\%, and 14\%, respectively. ApoE genotypes have different affinities for LDLR, with ApoE2 having the weakest binding to LDLR at ApoE3 > ApoE2 $)^{[6,8,11,13,16,43-45]}$. We suggest that a peptide targeting the ApoE LDLR binding domain may work as a competitive antagonist for patients who are ApoE4 carriers, in effect creating a more ApoE2-like structure [Figure 1].

Creating a more ApoE2-like structure may be associated with greater likelihood of survival to advanced 
age, superior verbal learning abilities, improved recall memory, faster processing of information, better test performance, and reduced accumulation of amyloid pathology in the aged brain. Furthermore, a second innovative approach would be to create a more advanced antibody targeting specifically the 133-152 N-terminal binding region of ApoE to prevent interaction between LDLR and ApoE. In sum, modulation of ApoE structure to create and/or enhance ApoE2-like activity may shed light on a novel approach for AD treatment and prevention.

\section{DECLARATIONS}

\section{Authors' contributions}

Reviewed the literature and wrote this article: Leon $\mathrm{M}$

Edited and added further information to this article: Sawmiller D, Giunta B

Contributed to the initial idea of the review: Tan J

Read and approved this article: all authors

\section{Availability of data and materials}

Not applicable.

\section{Financial support and sponsorship}

This work was supported by the NIH/NIA (R21AG049477, JT) and Silver Endowment (JT). JT holds the Silver Chair in Developmental Neurobiology.

\section{Conflicts of interest}

All authors declared that there are no conflicts of interest.

\section{Ethical approval and consent to participate}

Not applicable.

\section{Consent for publication}

Not applicable.

\section{Copyright}

(c) The Author(s) 2018.

\section{REFERENCES}

1. Sato N, Morishita R. The roles of lipid and glucose metabolism in modulation of B-Amyloid, tau, and neurodegeneration in the pathogenesis of Alzheimer disease. Front Aging Neurosci 2015;7:199.

2. Shafiei SS, Guerrero-Munoz MJ, CastilloCarranza DL. Tau oligomers: cytotoxicity, propagation, and mitochondrial damage. Front Aging Neurosci 2017;9:83.

3. Hoglund K, Kern S, Zettergren A, BorjessonHansson A, Zetterberg H, Skoog I, Blennow K. Preclinical amyloid pathology biomarker positivity: effects on tau pathology and neurodegeneration. Transl Psychiatry 2017;7:e995.

4. Polvikoski T, Sulkava R, Haltia M, Kainulainen K, Vuorio A, Verkkoniemi A, Niinistö L, Halonen P, Kontula K. Apolipoprotein E, dementia, and cortical deposition of beta-amyloid protein. N Engl J Med 1995;333:1242-7.

5. Kok E, Haikonen S, Luoto T, Huhtala H, Goebeler S, Haapasalo H, Karhunen PJ. Apolipoprotein E-dependent accumulation of Alzheimer disease-related lesions begins in middle age. Ann Neurol 2009;65:650-7.

6. Liu CC, Kanekiyo T, Xu H, Bu G. Apolipoprotein E and Alzheimer disease: risk, mechanisms and therapy. Nat Rev Neurol 2013;9:10618.

7. Elshourbagy NA, Liao WS, Mahley RW, Taylor JM. Apolipoprotein E mRNA is abundant in the brain and adrenals, as well as in the liver, and is present in other peripheral tissues of rats and marmosets. Proc Natl Acad Sci U S A 1985;82:203-7.

8. Zhao N, Liu C, Qiao W, Bu G. Apolipoprotein E, receptors and modulation of Alzheimer's disease. Biol Psychiatry 2018;83:347-57.

9. Zannis VI, Breslow JL. Human very low density lipoprotein apolipoprotein E isoprotein polymorphism is explained by genetic variation and posttranslational modification. Biochemistry 1981;20:1033-41.

10. Khan W, Giampietro V, Banaschewski T, Barker GJ, Bokde AL, Büchel C, Conrod P, Flor H, Frouin V, Garavan H, Gowland P, Heinz A, Ittermann B, Lemaître H, Nees F, Paus T, Pausova Z, Rietschel M, Smolka MN, Ströhle A, Gallinat J, Vellas B, Soininen H, Kloszewska 
I, Tsolaki M, Mecocci P, Spenger C, Villemagne VL, Masters CL, Muehlboeck Js, Bäckman L, Fratiglioni L, Kalpouzos G, Wahlund L, Schumann G, Lovestone S, Williams SC, Westman E, Simmons A; Alzheimer's Disease Neuroimaging Initiative; AddNeuroMed Consortium, Australian, Imaging, Biomarkers, and Lifestyle Study Research Group; IMAGEN consortium. A multicohort study of ApoE e4 and amyloid-B effects on the hippocampus in Alzheimer's disease. J Alzheimers Dis 2017;56:1159-74.

11. Bu G. Apolipoprotein E and its receptors in Alzheimer's disease: pathways, pathogenesis and therapy. Nat Rev Neurosci 2009;10:33344.

12. Mahley RW. Apolipoprotein E: from cardiovascular disease to neurodegenerative disorders. J Mol Med 2016;94:739-46.

13. Davignon J, Gregg RE, Sing CF. Apolipoprotein E polymorphism and atherosclerosis. Arteriosclerosis 1988;8:1-21.

14. Namba Y, Tomonaga M, Kawasaki H, Otomo E, Ikeda K. Apolipoprotein E immunoreactivity in cerebral amyloid deposits and neurofibrillary tangles in Alzheimer's disease and kuru plaque amyloid in Creutzfeldt-Jakob disease. Brain Res 1991;541:163-6.

15. Castellano JM, Kim J, Stewart FR, Jiang H, DeMattos RB, Patterson BW, Fagan AM, Morris JC, Mawuenyega KG, Cruchaga C, Goate AM, Bales KR, Paul SM, Bateman RJ, Holtzman DM. Human apoE isoforms differentially regulate brain amyloid-b peptide clearance. Sci Transl Med 2011;3:89ra57.

16. Chetty PS, Mayne L, Lund-Katza S, Englander SW, Phillips MC. Helical structure, stability, and dynamics in human apolipoprotein E3 and E4 by hydrogen exchange and mass spectrometry. Proc Natl Acad Sci U S A 2017;114:968-73.

17. Dong LM, Weisgraber KH. Human apolipoprotein E4 domain interaction: arginine 61 and glutamic acid 255 interact to direct the preference for very low density lipoproteins. J Biol Chem 1996;271:19053-7.

18. Mahley RW. Apolipoprotein E: cholesterol transport protein with expanding role in cell biology. Science 1988;240:622-30.

19. Urfer-Buchwalder A, Urfer R. Identification of a NRF1 recognition motif in the ApoE4 variant linked to AD. Sci Rep 2017;7:40668.

20. Chu Q, Diedrich JK, Vaughan JM, Donaldson CJ, Nunn MF, Lee KF, Saghatelian A. HtrA1 proteolysis of ApoE in vitro is allele selective. J Am Chem Soc 2016;138:9473-8.

21. Lane-Donovan C, Herz J. ApoE, ApoE receptors, and the synapse in Alzheimer's disease. Trends Endocrinol Metab 2016;28:273-84.

22. Pohlkamp T, Wasser CR, Herz J. Functional roles of the interaction of APP and lipoprotein receptors. Front Mol Neurosci 2017;10:54.

23. Fan QW, Iosbe I, Asou H, Yanagisawa K, Michikawa M. Expression and regulation of apolipoprotein E receptors in the cells of the central nervous system in culture: a review. J Am Aging Assoc 2001;24:1-10.

24. Kim J, Castellano JM, Jiang H, Basak JM, Parsadanian M, Pham V, Mason SM, Paul SM, Holtzman DM. Overexpression of lowdensity lipoprotein receptor in the brain markedly inhibits amyloid deposition and increases extracellular A beta clearance. Neuron 2009;64:632-44

25. Fryer JD, Demattos RB, McCormick LM, O’Dell MA, Spinner ML, Bales KR, Paul SM, Sullivan PM, Parsadanian M, Bu G, Holtzman $\mathrm{DM}$. The low density lipoprotein receptor regulates the level of central nervous system human and murine apolipoprotein $\mathrm{E}$ but does not modify amyloid plaque pathology in PDAPP mice. J Biol Chem 2005;280:25754-9.

26. Basak JM, Verghese PB, Yoon H, Kim J, Holtzman DM. Low-density lipoprotein receptor represents an apolipoprotein E-independent pathway of Ab uptake and degradation by astrocytes. J Biol Chem 2012;287:13959-71.

27. Koistinaho M, Lin S, Wu X, Esterman M, Koger D, Hanson J, Higgs R, Liu F, Malkani S, Bales KR, Paul SM. Apolipoprotein E promotes astrocyte colocalization and degradation of deposited amyloid-beta peptides. Nat Med 2004;10:719-26.

28. Hatters DM, Peters-Libeu CA, Weisgraber KH. Apolipoprotein E structure: insights into function. Trends Biochem Sci 2006;8:445-54.

29. Huang YA, Zhou B, Wernig M, Südhof TC. ApoE2, ApoE3, and ApoE4 differentially stimulate APP transcription and Ab secretion. Cell 2017;168:427-41.e21.

30. Maurice R, Marcel YL, Innerarity TL, Milne RW. A potential complication in the use of monoclonal antibodies: inhibition of apoBmediated receptor binding by an anti-apoE antibody. J Lipid Res 1989;30:587-96.

31. Raffai R, Weisgraber KH, MacKenzie R, Rupp B, Rassart E, Hirama T, Innerarity TL, Milne R. Binding of an antibody mimetic of the human low density lipoprotein receptor to apolipoprotein E is governed through electrostatic forces. J Biol Chem 2000;275:7109-16.

32. Grothe MJ, Villeneuve S, Dyrba M, Bartres-Faz D, Wirth M. Multimodal characterization of older APOE2 carriers reveals selective reduction of amyloid load. Neurology 2017;88:569-76.

33. Xue-Shan Z, Juan P, Qi W, Zhong R, Li-Hong P, Zhi-Han T, Zhi-Sheng J, Gui-Xue W, Lu-Shan L. Imbalanced cholesterol metabolism in Alzheimer's disease. Clin Chim Acta 2016;456:107-14

34. Suri S, Heise V, Trachtenberg AJ, Mackay CE. The forgotten APOE allele: a review of the evidence and suggested mechanisms for the protective effect of APOE e2. Neurosci Biobehav Rev 2013;37:2878-86.

35. Hamanaka H, Katoh-Fukui Y, Suzuki K, Kobayashi M, Suzuki R, Motegi Y, Nakahara Y, Takeshita A, Kawai M, Ishiguro K, Yokoyama M, Fujita SC. Altered cholesterol metabolism in human apolipoprotein E4 knock-in mice. Hum Mol Genet 2000;9:353-61.

36. Wilson RS, Bienias JL, Berry-Kravis E, Evans DA, Bennett DA. The apolipoprotein E epsilon 2 allele and decline in episodic memory. J Neurol Neurosurg Psychiatry 2002;73:672-7.

37. Fagan AM, Watson M, Parsadanian M, Bales KR, Paul SM, Holtzman DM. Human and murine ApoE markedly alters A beta metabolism before and after plaque formation in a mouse model of Alzheimer's disease. Neurobiol Dis 2002;9:305-18.

38. Drouet B, Fifre A, Pinçon-Raymond M, Vandekerckhove J, Rosseneu M, Guéant JL, Chambaz J, Pillot T. ApoE protects cortical neurones against neurotoxicity induced by the non-fibrillar C-terminal domain of the amyloidbeta peptide. J Neurochem 2001;76:117-27.

39. Dumanis SB, Tesoriero JA, Babus LW, Nguyen MT, Trotter JH, Ladu MJ, Weeber EJ, Turner RS, Xu B, Rebeck GW, Hoe HS. ApoE4 decreases spine density and dendritic complexity in cortical neurons in vivo. J Neurosci 2009;29:15317-22.

40. Miyata M, Smith JD. Apolipoprotein E allele-specific antioxidant activity and effects on cytotoxicity by oxidative insults and betaamyloid peptides. Nat Genet 1996;14:55-61.

41. Zhong N, Weisgraber KH. Understanding the association of apolipoprotein E4 with Alzheimer disease: clues from its structure. J Biol Chem 2009;284:6027-31.

42. Xu Q, Brecht WJ, Weisgraber KH, Mahley RW, Huang Y. Apolipoprotein E4 domain interaction occurs in living neuronal cells as deter- 
mined by fluorescence resonance energy transfer. J Biol Chem 2004;279:25511-6.

43. Corder EH, Saunders AM, Risch NJ, Strittmatter WJ, Schmechel DE, Gaskell PC Jr, Rimmler JB, Locke PA, Conneally PM, Schmader KE, Small GW, Roses AD, Haines JL, PericakVance MA. Protective effect of apolipoprotein E type 2 allele for late onset Alzheimer disease. Nat Genet 1994;7:180-4.

44. Wu L, Zhao L. ApoE2 and Alzheimer's disease: time to take a closer look. Neural Regen Res 2016;11:412-3.

45. Alzheimer's Association. 2012 Alzheimer's disease facts and figures. Alzheimers Dement 2012;8:131-68. 